\title{
Michaela Albl-Mikasa
}

\section{Express-ability in ELF communication*}

\begin{abstract}
In ELF research, ample evidence has been collected to show that communication in (dialogic) ELF interactions works and that it does so in intriguingly creative ways. In a questionnaire survey and an in-depth interview study, simultaneous conference interpreters present a less optimistic view with regard to (monologic) mediated multilingual settings, which are increasingly shaped by a growing number of non-native English-speaking participants. Moreover, the interpreters put the adverse effects of ELF speaker output on their cognitive processing down to the speakers' restricted power of expression. This is paralleled by empirical evidence from ELF speakers in TELF (the Tübingen English as a Lingua Franca corpus and database), who put into perspective their general feeling that they can cope in ELF interactions (which is in line with the ELF study findings mentioned above) by voicing dissatisfaction with their restricted capacity of expressing what they want to convey with the required or desired degree of precision.
\end{abstract}

In a theoretical discussion, the Express-ability Principle is introduced to capture the nature of the human effort for expression (complementary to Bartlett's effort after meaning). In the subsequent presentation, sociocultural and psycholinguistic research sheds light on express-ability in the context of ELF by applying Slobin's Thinking for Speaking (TFS) hypothesis to second-language contexts. It reveals the interface between verbal (L1) thinking and externalized (L2) speech and explains expression-related problems in terms of transfer effects in connection with age of acquisition and linguistic environment. This directs further ELF research into the nature of express-ability towards an examination of production processes, developmental and procedural aspects in early and late bilingual ELF speakers, a shared languages benefit to compensate for cross-linguistic transfer and the (relative) effectiveness of unmediated and mediated ELF communication.

Keywords: English as a lingua franca (ELF); conference interpreters; expressability principle; Thinking-for-Speaking (TFS); early and late bilingual ELF speakers; shared languages benefit.

\footnotetext{
* I should like to thank Robert DeKeyser, Kurt Kohn, Anna Mauranen, Tim McNamara, and Barbara Seidlhofer for mind-opening comments in personal communication and the two anonymous reviewers for comments that advanced my argument.
} 
'Express-ability' in der ELF-Kommunikation

Zusammenfassung: Eine Umfrage unter professionellen Konferenzdolmetschern sowie Interviews mit diesen Dolmetschern und mit ELF-Sprechern aus dem TELFKorpus verweisen auf einen Widerspruch zwischen dem allgemeinen Eindruck von ELF-Sprechern, dass sie in der Kommunikation zurechtkommen (was Forschungsergebnissen eines strategischen Funktionierens in ELF-Interaktionen entspricht) und ihrer Unzufriedenheit mit den eigenen eingeschränkten Ausdrucksmöglichkeiten (die Dolmetscher wiederum als Verarbeitungshindernisse erleben). Mit der Einführung des "express-ability principle” lässt sich das menschliche Bedürfnis nach Ausdrucksfähigkeit ausbuchstabieren. Die im Rahmen soziokultureller und psycholinguistischer Forschung erfolgte Anwendung von Slobins “Thinking for Speaking” (TFS)-Hypothese auf Zweitsprachkontexte gibt Aufschluss über “express-ability” im Kontext von ELF. Der genannte Widerspruch lässt sich vor diesem Hintergrund über vom Spracherwerbsalter abhängige Transfereffekte und Zusammenhänge zwischen verbalem (L1) Denken und externalisiertem (L2) Sprechen erklären. Hieraus lassen sich neue Forschungsperspektiven ableiten, die den Akzent auf Produktionsprozesse, entwicklungsabhängige und prozedurale Aspekte der ELF-Kommunikation, den Vorteil geteilter Sprachen ("shared languages benefit") zum Ausgleich von sprachübergreifendem Transfer und Unterschiede in der (relativen) Effektivität der Kommunikationsmöglichkeiten unter ungemittelten und gemittelten Bedingungen setzen.

Schlagworte: Englisch als Lingua Franca (ELF); Konferenzdolmetscher; "Expressability Principle”; “Thinking-for-Speaking” (TFS); frühe und späte Bilinguale; Vorteil geteilter Sprachen ("Shared languages benefit”).

Michaela Albl-Mikasa: Zurich University of Applied Sciences.

E-mail: michaela.albl-mikasa@zhaw.ch

\section{Introduction}

A major body of research into ELF deals with how lingua franca communication is successful without reliance on and mastery of native-speaker English forms. It goes to show that it is on the basis of pragmatic, intercultural, and collaborative skills, accommodation and negotiation strategies, and the creative appropriation of linguistic resources (cf. Jenkins et al. 2011; Seidlhofer 2011; Mauranen 2012) that meaning negotiation and mutual intelligibility are secured. In my work in 
the context of interpreting studies and the TELF (Tübingen English as a Lingua Franca) research group, I have been confronted with less optimistic views of ELF communication. Interpreters, who mediate between (a rapidly increasing number of) non-native English speakers and a target language audience or between native speakers of various first languages and an audience for which the English they receive from the interpreters is not their mother tongue, or even between non-native speakers at both the speaking and receiving end, observe that, in mediated bilingual settings, ELF communication is not always effective and that many non-native English speakers at conferences have difficulties in expressing the point they want to make. ELF speakers from the TELF corpus, moreover, report that they are not always satisfied with the extent to which they can fulfill their subjectively felt needs to fully express themselves.

In the following paper, I will first outline perceptions of (T)ELF speakers and interpreters reported in three studies based on interview data and, thus, individual observations rather than factual evidence. However, the points made are interesting in themselves and provide motivation to look into the expression side of ELF communication. The paper, therefore, continues with a theoretical development of "express-ability," which is a notion that deals with speakers' ability to give expression to what they intend to say, just as comprehensibility, intelligibility, and related notions (cf. Pickering 2006) capture recovery of meaning by the hearer. The final part of the paper draws on psycholinguistic evidence from research into bilingualism and, more specifically, on the application of neoWhorfian work to second-language contexts to illustrate the significance of express-ability for the study of ELF. The ability to express oneself - which is of concern to any (monolingual or multilingual) language user - manifests in the step from mental concepts/thinking to verbal expression/speaking. In research into bilingualism, experimental and naturalistic studies have come up with nuanced approaches to the study of ways in which cross-linguistic differences correspond to different conceptual representations and lead to differences in thought processes; it is found that it is not only the structural patterns of languages, but also discourses as social practices associated with various contexts that influence construction of the world and result in differences in verbal performance (cf. Pavlenko 2005). Against this background, it can be shown how differences in age of acquisition, L2 socialization, and language proficiency significantly affect the way in which ELF speakers organize conceptual material for expression and how their ability to express themselves is a relative matter, in view of the numerous factors that impact upon the process. 


\section{From intelligibility to express-ability}

In one of three studies, a questionnaire survey among 32 professional conference interpreters, the respondents agreed that the spread of ELF adversely affected their work on the macro-level (e.g., professional standing, job satisfaction) as well as on the micro-level (regarding comprehension and production processes and capacity management) (cf. Albl-Mikasa 2010). Research in the context of interpreting studies shows that ELF-induced interpreter difficulties are, to a great extent, related to the bilingual and mediated processing conditions and task requirements specific to the specialized activity of simultaneous interpreting. Problems arise on the basis of "monologic speech events that offer little or no room for interaction" (Reithofer 2010: 149) and from the obstruction of activation and retrieval of trained and established links between source and target language items, settled transfer routines, and ready-to-use translation equivalents by non-conventional ELF performance (cf. Albl-Mikasa forthcoming). In the interpreters' view and experience, it is the lack of a certain power of expression on the part of the non-native source text producers that is behind the problems and adversely affects their work. Well aware of the fact that native English output (e.g., from a Northern English football player) can be harder to interpret than that of, say, a non-native Scandinavian academic (cf. Albl-Mikasa 2010: 134-135), they overwhelmingly agreed that non-native speakers on the whole posed a greater challenge. In answer to the question as to whether they preferred native or non-native English source text producers, a clear majority $(69 \%)$ of respondents preferred source text production by native speakers and only 6\% by non-native speakers (22\% no preference, 3\% no reply) (cf. 2010: 130). The reasons given in favor of the native speakers were, among others, "reliable structures and correct expressions", "deliberate and purposeful use of concepts and terms", "more accurate expressions", "fewer mistakes and false friends", "clearer, more logical and more differentiated argumentation", "can get their message across", and "easier to follow what they are getting at" (2010: 135).

These are, for the moment, reported views of individual interpreters and I will elaborate more extensively on the interpreters' perceptions and on why they may be more than just anecdotal evidence in a paper under preparation. As they stand here, these views are tokens of my motivation to look into the expression side of ELF. The same applies to another interesting point made in in-depth interviews of ten professional conference interpreters (for details of the 90,000 word corpus, see Albl-Mikasa 2012). They stressed that foreign pronunciation and accents of ELF speakers were only part of the problem and greater difficulty arose from the tendency of those speakers to heavily rely on their L1 when expressing 
themselves, that is, to transcode typical (idiomatic, collocational, and other phraseological) L1 structures into English. Examples mentioned were, among many others, the frequent words of welcome by German speakers of we hardly welcome you (based on the German herzlich willkommen heißen) instead of 'we heartily/ whole-heartedly welcome you' (I-8) ${ }^{1}$; their literal English translation of typical L1 structures, such as it will be sinful to do something (from German sinnvoll meaning 'make good sense/useful'); or this is not the yellow of the egg (from German das Gelbe vom Ei, which means 'brilliant') (I-6); or an Italian talking about voices in the context of accountancy (I-4), which will only be properly understood by an interpreter who knows that in Italian voce refers not only to 'voice', but also to an item on a balance sheet. The interpreters interviewed made it clear that it was this 'L1-colored' way of expressing things on the part of the non-native speakers that made interpreting increasingly difficult especially for those interpreters who did not have the non-native speaker's mother tongue as one of their working languages.

Research into interpreting has, in fact, produced a number of case studies to the effect that knowing the non-native speaker's mother tongue (i.e., having it as one of one's working languages) greatly facilitates the interpreter's task (cf. Taylor 1989; Basel 2002; Kurz and Basel 2009). This is also confirmed by one of Germany's top conference interpreter team organizers (in personal communication), who reports the increasing need to take into account not only the conference languages, but also the speakers' L1s in contracting interpreters. What I would term the shared languages benefit is not restricted to the interpreters' experience, ${ }^{2}$ nor is it restricted to the speakers' L1. As has been discussed for some time and is also found in a study on Eastern European English, not only speakers' L1, but also their L3 may influence the structures and vocabulary used as ELF, so that there are types of "literal translation" where "sharing a common language is essential” (Salakhyan 2012: 341).

Interestingly, the interpreters' perceptions tied in with primary ELF speakers' reports of dissatisfaction with difficulties of expressing themselves in ELF communication. An analysis of TELF (Tübingen English as a Lingua Franca corpus and database) interview data (cf. http://www.telf.uni-tuebingen.de) of 34 non-native speakers, who had been retrospectively questioned following ELF

1 The ten interviewees in my 2012 study were coded and referenced as I-1 to I-10.

2 I am aware of Bent and Bradlow's (2003: 1606) notion of "matched interlanguage intelligibility benefit," but believe the use of the concept of "interlanguage" to be rather unfortunate in the context of ELF. 
interactions in discussion groups of on average four participants, ${ }^{3}$ revealed that the struggle for expression was of major concern for them (for details of the study, see Albl-Mikasa 2009). In fact, there was a contradiction between a general feeling of satisfaction with ELF communication and the impression that they could cope in ELF interactions, on the one hand, and their being at odds with the lack of being able to express more precisely what exactly they wanted to say, on the other: In answer to the question as to whether they felt that their English was sufficient for their needs and purposes, $85 \%$ of them felt that this was actually the case. At the same time, a great number of the qualitative statements to the openended questions pointed to a common phenomenon amongst ELF speakers that could be described as the 'my-English-sucks-feeling' (in fact, the word "suck" appeared several times in this context). One of the interviewees that used this s-word explained the feeling in the following way:

My English sucks. I'm looking for some words but they don't come to me and I have really problem to express myself [...]. I'm looking for time for actually think how the best way to express myself [...]. [In Czech] I can operate a lot [...] more with the words I can just precisise the meaning so the others have some feelings I want them to have in English. (Midw_08_NNSD_04, Ja_008_Cz_f)

Evidence that this informant did indeed have problems in expressing herself can be found in the actual discussion output data (the topic of the discussions being intercom systems designed to help prevent sudden infant death syndrome), where one finds that this (Czech) non-native participant $\left(\mathrm{P}_{1}\right)$ in the ELF discussion was uncertain about how to put certain things. Thus, in the retrospective interviews, one of the fellow participants $\left(\mathrm{P}_{2}\right)$ in the discussion admitted to having opted out at some point. When retrospectively commenting on some of the performance data, $\mathrm{P}_{2}$ said "I think at this point I stopped listening", which was in reaction to the following turn by $\mathrm{P}_{1}$ :

3 The special feature of TELF is that it combines conversational ELF output data from transcribed discussions with introspective and retrospective interview accounts addressing the participants' learning history, their English requirement profile, and their performance in the discussion. While the focus of my 2009 study was on the interlocutors' interview statements (i.e., the answers to 13 open-ended questions), regarding their attitudes towards ELF and their performance in the discussion, a number of seminar papers and master theses (some of which I co-evaluated) provided results based on analyses of the transcribed performance data. Moreover, four major PhD projects are underway, considering the 'triangulated' data (see the TELF research team on the TELF website). 
no we have to speak to other company because we didn't produce it but the problem is the our intercom so we can tell that the problem is on this side and work with the other company because they know who bought it and call it back and just change the our part. (Midw_08_NNSD_04; 63)

Looking at the discussion output data of a Spanish participant (from another discussion group on the same topic), who had used the word "suck" in the interview, one finds (among other problems) the following lexical retrieval problem (in relation to the word "company"):

\footnotetext{
But we are not speaking about drinking water we are oh we are speaking about that a baby can die and angry parents can say: Okay, $\mathrm{f}^{\star \star} \mathrm{k}$ everything ... I am going to ... - I'm going to destroy this ... this ... this ... uum ... (laughs) ... what he does like this enterprise because they have killed my baby. People can do that. (Midw_07_MON_03; 259)
}

Finally, interview statements along similar lines were made, such as: "the hardest thing is to express exactly what I'm trying to say, saying it fully"; "I wanted to make a point but the [. . .] keyword [. . . I I just couldn't make it up" (for more statements and the respective respondents, see Albl-Mikasa 2009: 121, 125, 126; for more examples of problems of expression in the TELF discussions output data, see Kress 2010). In summary, non-native ELF speakers tend to feel quite strongly about their (more and less severe) difficulties in expressing themselves at a level of precision they deem desirable. The "struggle in language processing" (James 2005: 139) is, finally, also found by James for less proficient ELF speakers.

In conclusion to this short presentation of the three studies described above, it may be said that ELF speakers and ELF speech mediators rather emphatically point to the ability to express oneself as an important dimension of ELF communication. Interpreters will highlight this dimension not least because they take the comprehension side for granted; they are trained, in an extreme sense, for and in understanding and coherence building. As the very word "interpreting" suggests, they are almost tuned into and conditioned towards making sense of any speaker's output and will achieve (some) understanding even under the most adverse processing conditions (cf. Albl-Mikasa 2012: 73) and on the basis of a wide range of accents, whether native (Scottish, Australian, Texan, etc.) or nonnative (international Englishes). Primary ELF speakers, for their part, are somewhat torn between the opposite forces of their general ability to cope in ELF communication and their restricted ability to make and argue their point well enough.

Given the introspective nature of the interpreters' reports and the need to align the TELF participants' interview statements with their actual performance in the discussions more systematically, much more research has to be conducted into the exact nature of ELF speakers' difficulties of expression and the actual 
nature of interpreter problems in mediating ELF communication. At the same time, evidence suggests that it would be a reductionist view to put expressionrelated problems and complaints down to the respondents' traditional ELT (English Language Teaching) background and entrenched native-speaker ideals alone. Against this backdrop, the ability to express oneself seems to deserve greater attention than it has received so far in the academic discussion of ELF. In what follows, I will present a theoretical development of the notion of expressability and psycholinguistic evidence for why it may be of significance for the study of ELF.

\section{Effort after meaning and for expression}

In general terms, speakers use linguistic means of expression to serve their communicative needs and purposes and to fulfill their own "self-imposed communication and community-oriented requirements" (Kohn 2011: 81). In the case of ELF speakers, such requirements concern in particular

comprehensibility and self-expression, compliance with a target language model (which is not necessarily Standard English) regarding grammatical accuracy and situational appropriateness, participation in a speech fellowship or expression of my self. (Kohn 2011: 81, emphasis added)

While the expression of one's self may be seen to manifest in people's desire to express themselves in fine arts, music, drama, dancing, poetry, creative writing, martial arts, competitive sports, or other output and performance-oriented activities, people's requirement for self-expression is of a more basic and languagerelated nature. Describing, from a sociocultural theory (SCT) point of view, the three fundamental cultural factors (activities, artifacts, and concepts) that "mediate the relationships between people, between people and the physical world, and between people and their inner mental worlds” Lantolf (2006: 69) presents the capacity to use language (to mediate mental activity) as "the most powerful of our mediational artifacts." Self-expression as part of the cultural artifact of language is complementary to Bartlett's (1932: 227) fundamental "effort after meaning” (see below). As also captured in principles such as the Principles of Analogy and Local Interpretation (Brown and Yule 1983: 58-66) or the Principle of Relevance (Sperber and Wilson 1995 [1986]), human cognition is principally geared towards making sense and achieving understanding and "[t]he natural effort of hearers and readers alike is to attribute relevance and coherence to the text they encounter until they are forced not to" (Brown and Yule 1983: 66, emphasis added). Similarly, the natural effort of speakers will be to produce an utterance 
that gets across their communicative intention. I will formulate this effort in the following Express-ability Principle:

\begin{abstract}
Endowed with the capacity for language, human beings have a fundamental need and want to make use of linguistic resources to cast into expression what they mean (to say) at a level of abstraction, complexity, and precision that fits their intended purpose in a given context, and this, in turn, drives language acquisition and the development of communicative competence.
\end{abstract}

From this principle, it follows that people will not content themselves with mutual intelligibility, but that they will also strive to a greater and lesser degree for precision and clarity, stringency in the argumentation and rhetorical coherence, and a certain subtlety and delicacy in the nuances of their expressions. Their power of expression will depend on the availability of adequate resources. To the extent to which they lack these resources and cannot meet these requirements they will feel left behind and dissatisfied. It needs to be noted that such precision is not correlated with grammatical accuracy (although the latter may contribute to it), as seen from oral forms of communication and informal text types. Nonconformities in relation to a norm, for example, Standard English, such as omission of a third-person 's', addition of a plural 's' to uncountable nouns (e.g., informations), or non-standard suffixes (bigness, increasement), are irrelevant to the purpose. What is necessary is that people are able, that is, that they have the (inter-individual) means to make their point, or, to put it in the terms of Grice's maxims, that they are able to be relevant, "mannerful"/orderly, and qualitatively and quantitatively appropriate.

The Express-ability Principle differs markedly from Searle's Principle of Expressibility, "the principle that whatever can be meant can be said" (Searle 1969: 19) and Katz's Principle of Effability, which states that "[e]ach proposition can be expressed by some sentence in any natural language” (Katz 1978: 209). According to Katz, his principle was "propounded in somewhat different form" by Searle (and others). As Recanati (2003: 195) points out, the two principles are essentially “equivalent.” Katz's principle is about the relation between logic and language as the overall concern is what "a theory [of natural language] ought to say about the logical structure of sentences in natural language” (Katz 1978: 191). Katz briefly touches upon a psychological 'corollary' principle, which he interchangeably labels "expressability" and "expressibility" and which states that "[e]ach thought can be expressed by some utterance of a natural language" (1978: 217); in doing so, Katz accounts for the double function of the construct of propositions as (a) abstract entities ("senses of sentences", 1978: 201) and (b) "psychological objects of some sort, perhaps mentalistic constructions, perhaps certain kinds of brain states" (1978: 203). However, this second principle again 
"represents the idealised functional relation of language to mind" (1978: 217, emphasis added). Katz's aim is to provide a theoretical basis for "the thesis of the completeness of the semantic level of language and the power of the syntactic and phonological levels to express the objects at the semantic level” (1978: 215). The principle is, thus, clearly embedded in his Semantic Theory and exclusively refers to "propositional content" (1978: 223) and, thus, context-free meaning. In Recanati’s terms:

Katz defines the (grammatical) meaning of a sentence as the meaning it has in the "null context"; and he says that what the speaker means by uttering a sentence $\mathrm{S}$ in a context $\mathrm{C}$ (the "utterance meaning" of S) can always be made explicit as the "grammatical meaning" of an alternative sentence $S^{\prime}$ that the speaker might have uttered. (Recanati 2003: 195, emphasis added)

As for Searle's Principle of Expressibility, the central idea is that "it is always possible to utter a fully explicit sentence [. . .] whose linguistic meaning exactly corresponds to, and uniquely determines, the force and content of the speech act one is performing" (Recanati 2003: 193). This means that what is otherwise left to extra-linguistic pragmatic principles - elliptical, ambiguous, referential, implicit, indirect, ironic, or metaphorical dimensions of an utterance - can in principle be spelt out. Hence, the gist of the principle is that the gap between literal sentence meaning and the (speaker's) utterance meaning can always be closed (cf. 2003: 193).

From a contextualist perspective, however, Recanati makes it clear that underdetermination of communicated content by linguistic meaning is an essential feature of linguistic communication and that "the sort of content that utterances have [...] can never be fully encoded into a sentence” (Recanati 2003: 194). Especially,

it is impossible to make explicit the background assumptions against which an utterance is interpreted - first, because there is an indefinite number of such assumptions, and second, because one cannot make them explicit without bringing in further background assumptions against which the new descriptive material is interpreted. (Recanati 2003: 194)

As a result, Recanati questions the Principle of Expressibility as a whole. It should be noted that the Principles of Expressibility and Effability are constructs of the late 1960s and early 1970s and, thus, reflect the concerns of that time: the (earlier) turn from semantic theory to pragmatics, the step from language (the language of an ideal speaker) to speech (language in use). A later attempt to bridge the gap between sentence and utterance meaning is Sperber and Wilson's 1995 [1986] Relevance Theory, which takes into account context, background assumptions, 
inferential processing, and what is actually and intentionally communicated. Developing further Grice's distinction of the two levels of meaning (what is said and what is meant), they introduce a third level, that of the "explicature" (1995 [1986]: 182). In their cognitive approach, they take great pains to detail the (explicating) processes (reference assignment, disambiguation, enrichment) by which the propositional skeleton of an utterance is fleshed out into a full proposition as intended by the speaker (which is the explicature). The interesting point here is that this development of the incomplete logical form or semantic representation of an utterance is not done exhaustively, but that the process is constrained by the Principle of Relevance and stops at the point where relevance is achieved. Relevance is conceived as a function of or trade-off between processing effort expended and cognitive effects gained and is inherent in cognitive processing since, according to the Principle of Relevance, all human beings automatically aim for the most efficient information processing possible (cf. 1995 [1986]: 49). The Principle of Relevance is, thus, not about full explicitation of non-explicit utterance meaning (as are the Principles of Expressibility and Effability), but about the inferential cognitive process whereby a hearer recovers intended (utterance) meaning in an actual communicative interaction.

Even though Sperber and Wilson claim to account for communication as a whole, recovery of utterance meaning by means of inferential explicating and implicating processes is what their theory focuses on; it only briefly touches upon the communicator side (ostension) that they claim to cover:

Inferential communication and ostension are one and the same process, but seen from two different points of view: that of the communicator who is involved in ostension and that of the audience who is involved in inference. (Sperber and Wilson 1995 [1986]: 54)

Relevance Theory is, in fact, a micro-pragmatic approach with a rather narrow propositional focus. It has been criticized for not accounting for the schematheoretic underpinnings that are fundamental for any explanation of inferential processing, or, more precisely, for not linking back the central notion of contextual assumptions to the procedural aspects they depend on (cf. Widdowson 2004: 44-47, 52). Sperber and Wilson's neglect is, indeed, astounding insofar as, in that very period (of the cognitive turn of the 1980s), constructivist views of language and text processing based on schema-theoretic notions became increasingly important. From that perspective, any account of utterance processing, economy in language use, and linguistic underdeterminacy rests (roughly speaking) on bottom-up/top-down interactions, recourse to (schematic) background knowledge, and the drawing of inferences. Under this paradigm, language processing is explained in terms of the building of mental representations (at local and global 
levels) through activation of schematic knowledge structures (cf. Van Dijk and Kintsch 1983; Brown and Yule 1983).

The influence of schemata on meaning construction goes back to Bartlett's 1932 "study in experimental and social psychology," where he empirically demonstrated that everyday remembering operated on what he called "effort after meaning," that is, striving to connect something given to some past experience, which is organized in schematic knowledge structures. It underlines the role of experience and expectation in meaning construction and that much of what is understood is inferred. Complementary to the effort after meaning, the Expressability Principle deals, from a socio-psychological perspective, with the effort for expression. It is not (different from the Principles of Expressibility and Effability) about potentiality in the sense of the potential of language to encode and make explicit propositional meaning or the possibility of carrying over utterance meaning into sentence meaning, but about the actual ability and effort of speakers to use language (and make use of linguistic resources) in real communication under the conditions of cognitive language processing and under the influence of a great number of factors from the communicative situation or setting. Moreover, in contrast to the Principle of Relevance, it does not take the perspective of the inferential recovery of utterance meaning (by developing and explicating the intended proposition), but that of the speaker striving to make an optimally relevant linguistic contribution in expressing his intended utterance and of his ability to organize that contribution and make it available. Express-ability is, thus, about 'propositionalizing' and then casting propositional meaning into communicable expression. It is, therefore, about the step from conceptual thought to actual language (use), or from thinking to speaking.

What does this mean for the study of ELF? If, as suggested in Section 2 above, (mutual) intelligibility is perceived to be something that is, in general, somehow strategically achieved, and if the lack of express-ability is felt more strongly as more and more people use ELF or are confronted with the use of ELF, one may ask which factors or forces hamper ELF speakers' ability to express what they want to convey in ELF contexts, while they feel, at the same time, that they can, in general, cope quite well. I will draw on insights from sociocultural and psycholinguistic research to try to shed some light on this apparent contradiction.

\section{Thinking (mother tongue) for speaking (non-native English)}

In studies with bilinguals, "strong evidence" has accumulated in support of L1based conceptual transfer, that is, the L1-based conceptual system guiding at 
least the beginning and intermediate stages of L2 learning and use (Pavlenko 2005: 438, 446). Kroll and Stewart (1994) argue that second languages with low proficiency levels require mediation of the first language. Non-native speakers will, therefore, up to a certain proficiency level, have to or be likely to think in their L1 and translate their meaning intentions from L1 thought into L2 speech. In this connection, Slobin's (1996) Thinking for Speaking (TFS) hypothesis offers valuable clues for a further examination of questions relating to express-ability and ELF.

At the core of Slobin's original hypothesis is the close interrelation between thinking/conceptualization and speaking/formulation. Slobin takes the Whorfian debate (on how far thought is determined by language) from the level of abstract constructs (thought and language) to that of mental processes (thinking and speaking). At this level, it is inevitable that experience or the conceptualization thereof is to a certain extent structured by the grammatical categories of a particular language. In the online process of converting thought into words, chunks of conceptual structure have to be matched with lexical meaning specifications. In other words, in the activity of speaking, thinking takes on a particular quality as experiences are filtered through languages into verbalized events (Slobin 1996). This process of having to fit thought or conceptual structure into the given grammatical categories of language or available and readily encodable linguistic frames is in line with Levelt's "regimentation of thought" in his 1989 speech production theory; it implies that there is not only an influence of thinking on speaking, that is, on how people talk about events, but that speaking also influences how people think about things (and, thus, experience events). The impact of the grammar of a language is explained by the likelihood that experience is mentally encoded in such a way that it is easier to express it in linguistic categories thereafter, since for "prelinguistic or nonlinguistic coding” during experience time, people will attend "to those event dimensions that are relevant for linguistic coding” at speaking time (Slobin 2003: 179).

Within the framework of TFS theorizing (Slobin 1996, 2003), it has been shown that speakers of different languages, while using the same words, perceive and think about the same event in markedly different ways (cf. Lantolf 2006: 79) and that "languages differ with regard to TFS features, including temporal marking, spatial encoding and motion events" (2006: 77). A case in point is the great number of English verbs that conflate motion and manner, which results in English speakers being much more likely than their Spanish counterparts to develop a "rich mental imagery of manner of motion" so that the "manner of motion will be salient in memory of events and in verbal accounts of events" (Slobin 2003: 164). As a consequence, English L1 speakers learning L2 Spanish will have to downplay their need for fine-grained descriptions of manner, while L1 Spanish 
learners of L2 English will have to develop a certain manner sensitivity and take on a new perspective on TFS about motion events. Lantolf (2006: 84) concludes that "[w]hat is at issue is not just communicating in a L2, but TFS through this new language."

These findings with regard to language-specific TFS differences are corroborated by psycholinguistic research. Investigating the construal of events by native speakers of English and German (who were also advanced L2 learners of the other language), Carrol and von Stutterheim (2003) found conditioning effects of language on event construal and observed that these effects become firmly established by the time a native speaker reaches early adolescence, so that the conditioning effects of the L1 are subsequently carried over into a person's reference to events in an L2. In more concrete terms, languages with the grammatical means of marking imperfective aspect sensitize their speakers to the phasal qualities of events; this greater sensitivity to the phasal qualities of ongoing events results in a defocusing of endpoints, thus making endpoints less relevant and consequently less frequently mentioned in descriptions of certain types of events. Therefore, speakers of languages with grammaticalized imperfective aspect (in this study, English speakers) have restricted time schemas that are generally more developed, more entrenched, and more readily activated than they would be for speakers of languages lacking grammaticalized imperfective aspect (in this study, German speakers). Carrol and von Stutterheim (2003: 393) conclude that L2 speakers are entrenched in L1 thinking and that the patterns of event conceptualization a person has acquired through the L1 are "highly resistant to reorganization" and will show up in L2 speech, as "grammaticalized conceptual categories play a predominant role in deciding how conceptual material is organized for expression" (von Stutterheim and Nüse 2003: 870, emphasis added).

This is, actually, in line with interpreter experience. A respondent in my 2012 interview study reported that "the wrong use of tenses" by non-native speakers (e.g., the Irish delegation asks for the floor instead of is asking) can give rise to "serious misunderstandings" (I-2). In the example mentioned, the Irish delegate had failed to understand that the chairman had actually given him the floor. Such misunderstandings can be explained by TFS-based findings that "the structural feature [+/- aspect] induces a specific pattern of event construal" (von Stutterheim and Nüse 2003: 870), so that a (native or highly proficient) speaker using the progressive form would highlight the ongoingness of an event, whereas not using this structural feature implies viewing the event in its entirety, as a complete act (of asking). In this case, the interpreter's experience contrasts with ELF(A) corpus research, which finds that miscommunication does not ensue from non-standard tense in L2 speech events (cf. Ranta 2006). It may, therefore, be fruitful to investigate in further studies whether tense-related problems are more likely to occur in 
native-non-native speaker communication (as was the case in the Irish delegation example) than in non-native-non-native speaker interaction (as in Ranta's analysis). From the interpreters' point of view, these are examples of adverse effects on communication that require knowledge of the structures underlying the speakers' L1 and influencing their lingua franca English. As the interpreter (I-2) who made the point about the Irish delegation put it: “[When people don't speak their own language], you can't follow their words very often, the way they think; I know the way a usual German thinks [. . .]" (cf. Albl-Mikasa 2012: 77). The shared languages benefit outlined in Section 2 above, thus, involves knowing how people of certain languages conceptualize things and how this is expressed in linguistic terms.

There is evidence that findings regarding strong L1 influence in the step from verbal thinking to externalized speech need to be seen in relation to speakers' language learning history. In their study of Hungarian learners of French, Russian, and English, Kecskes and Papp (2000: 102) found that these learners were more likely to rely on "L1-dominated metaphorical thinking" the lower their L2 proficiency. By contrast, under conditions of cultural immersion, L2 speakers are able to appropriate concepts and use them to mediate their thinking processes (cf. Lantolf 2006: 89). Psycholinguistic research finds, in fact, that the relationship between grammatical knowledge and patterns of conceptualization and subsequent ways of expression (or non-expression) on the part of non-native speakers depend on age of onset (AO) of language acquisition and on linguistic environment. Thus, L1 conceptualization that is resistant to change and unavoidably transferred to L2 usage as found in Carrol and von Stutterheim's (2003) study applied to adolescent (foreign language) English learners, who had remained in the L1 environment. Bylund and Jarvis (2011: 52), by contrast, looked into the interconnectedness between grammatical aspect and event conceptualization in bilinguals who had moved to the L2 environment before the age of 12 and whose contact with the L1 community had been reduced; what they find is "reverse construal transfer from L2 to L1." This supports the assumption that L2 influence depends on whether bilinguals had come into contact with the L2 before their patterns of L1 event-schema selection were firmly established or whether they had already developed stable preferences. Bylund and Jarvis (2011: 58) conclude that correlations between conceptualization patterns and proficiency with certain, specific grammatical structures can be found.

An important point here is that it is not only grammaticalized conceptual categories that influence the ways in which speakers of different languages tend to view and express events, or metaphorical thinking that comes under the influence of cross-linguistic transfer (cf. Kecskes and Papp's study above). Many languagespecific patterns of conceptualization may arise independent of the grammar of 
the language "only in the context of communication [...], as a person segments, selects, structures and linearly orders elements of a conceptual representation (e.g., of an event) for purposes of verbal expression" (Bylund and Jarvis 2011: 47-48). It is, therefore, not only entrenched grammatical categories but also cognitive patterns resulting from communication-specific conceptual distinctions that play a role in cross-linguistic transfer. This means that non-native speakers' speech may be greatly influenced by the conceptualization patterns they acquired as members of particular discourse communities (cf. 2011: 47).

What emerges from the research outlined above is that bilingualism produces a great variety of transfer effects and linguistic transitions, and that different types of bilinguals behave differently and develop different representations. This applies not only to early and late bilinguals. Even among late bilinguals, "speakers with minimal exposure to the target language may differ from L2 users socialized into the target language community" (Pavlenko 2005: 446). According to Pavlenko, language-influenced conceptual changes and, consequently, performance patterns appear to be affected by a great number of factors: "individual factors" (language learning history, proficiency, degree of acculturation), "interactional factors” (context of language interaction, familiarity with the speaker's language), and "linguistic and psycholinguistic factors" (degree of relatedness between the mental representations in the languages in question, degree to which the concept of one language could be expressed in the other language) (cf. 2005: 447).

In view of the enormous (linguistic and cultural) diversity among bilingual ELF speakers, this has interesting implications for the study of ELF. What is of relevance for the discussion of express-ability at this point is that, depending on these various factors, ELF speakers will have greater or lesser difficulties in the verbalization process and that it will be important to distinguish comprehension and production processes. Moreover, this (TFS-based) perspective directs attention to going beyond the present "focus in ELF research [...] on language use (rather than on development) and on the sociopragmatic functions of language choice” (House 2010: 368). While House's notions of “pragmatic fluency" (1999: 86) or "pragmatic competence" (2002: 262) are part and parcel of expressability in ELF speakers, the psycholinguistic perspective above makes it clear that the concept cannot be properly understood when excluding the developmental dimension. As Kohn emphasizes in his presentation of the "My English condition":

The English we observe in ELF situations only exists insofar as its speakers have acquired and developed it, i.e., insofar as its speakers have also been - and usually still are - learners of English in the broadest sense. Language learning is thus an inevitable and necessary condition of ELF. Trying to understand the nature of English in ELF situations should therefore be extended to also include its developmental matrix. (Kohn 2011: 80) 
A similar point is raised by McNamara in his conceptualization of ELF-oriented language testing and pedagogic evaluation:

\begin{abstract}
Moreover, while ELF research so far has tended to be principally linguistic and sociolinguistic in character, assessment requires the conceptualization of a learning dimension in ELF communication, that is, the notion of degrees of competence and the possibility of improvement or progress in the ability to manage this form of communication. (McNamara 2012a: 201)
\end{abstract}

In view of the interdependence of conceptualization/verbal thinking and verbalization/ externalized speech, the ability of speakers to express themselves in a second language, and more specifically, in English as a lingua franca, does not only have a developmental but also a procedural dimension, relating to issues such as processing, cognitive load management, or monitoring of ELF speech. ${ }^{4}$ The strain on cognitive resources in the struggle for self-expression may stand in the way of proper monitoring, which in turn may foster misunderstandings when speakers do not have enough resources to monitor, re-express, explain further, or adapt and coordinate their speech, which, in the end, may affect the overall development of an interaction in ELF communication.

\title{
5 Conclusion
}

Three studies of ELF speakers and conference interpreters mediating between ELF and native speakers of different languages draw attention to the expression side of ELF communication. On the basis of their everyday working experience, conference interpreters are less optimistic about the effectiveness of non-native speakers' use of ELF described by ELF researchers as functional and appropriate and they feel that the problems they observe are due to the non-native English speakers' difficulties in expressing their communicative intention (cf. Albl-Mikasa 2010). Although rooted in the specific setting of monologic mediated communication, this perception of non-native ELF speakers' restricted power of expression is not a singular view of interpreters because ELF speakers themselves voice their dissatisfaction with the extent to which they can fulfill their subjective needs for self-expression (cf. Albl-Mikasa 2009). In fact, what is found in the TELF corpus data is a contradiction between non-native speakers' feeling that they can cope in

4 Monitoring in the context of ELF is currently being investigated by one of the members of the TELF research team, Andreas Glombitza, as part of his PhD project (cf. http://www.telf. uni-tuebingen.de/). 
ELF communication and their dissatisfaction with their restricted ability on the expression side. Evidence from the three studies suggests that expression-related problems and complaints should not be put down to traditional ELT (English Language Teaching) backgrounds and entrenched native-speaker ideals alone.

Against this backdrop, I introduced the Express-ability Principle which points to the nature of the need and want of speakers to give expression to what they want to say. When applied to the non-native use of language, it goes beyond the notion of "pragmatic fluency" (House 1999), beyond mastering the appropriate use of gambits and other discourse markers. Express-ability is more deeply rooted in the closely intertwined development of conceptualization and verbalization processes and touches upon many non-native speakers having to express complex L1 thoughts through restricted L2 resources. Sociocultural and psycholinguistic research that applies Slobin's Thinking for Speaking (TFS) hypothesis to second-language contexts finds that the step from verbal thinking to externalized speech is strongly influenced by a speaker's L1 and that the organization of conceptual material for L2 expression is not only influenced, but may be hindered, by deeply entrenched L1 ways of viewing and expressing things (von Stutterheim and Nüse 2003). At the same time, there is evidence of a correlation of conceptualization patterns and proficiency with particular grammatical structures and with cognitive patterns specific to a context of communication and of a reverse L2 onto L1 transfer in early bilinguals (Bylund and Jarvis 2011).

On this basis, it becomes possible to provide psycholinguistic explanations for the above-mentioned contradiction between ELF users' feeling that they can cope (which is in line with ELF research findings to the effect that ELF communication works) and their being at odds with their (restricted) ability to express themselves, which needs further examination. What the overall analysis suggests is that the study of express-ability in ELF contexts can be advanced by differentiating between comprehension and production processes and between different types of bilingual non-native ELF speakers. Late bilingual speakers in ELF communication are likely to be strongly influenced by L1-specific ways of viewing and expressing things, whereas early bilingual speakers may be influenced by $\mathrm{L}_{2}$ or $\mathrm{L}_{\mathrm{x}}$ structures acquired from community-specific discourse in an $\mathrm{L}_{\mathrm{x}}$ environment. Since different conceptual patterns acquired as speakers of one language potentially transfer across languages and affect their use of another language, a shared languages benefit (which is part and parcel of the interpreters' experience) is likely to play an important role in ELF communication. At the same time, not being able to inhibit or control cross-linguistic influence can make the effort for expression quite a struggle and, at times, a dissatisfactory enterprise. Shifting the focus from intelligibility to express-ability and from across-the-board consideration of ELF speakers to one that includes age of onset (i.e., age of acquisition) brings in a 
developmental perspective, which until recently (cf. Kohn 2011; McNamara 2012a) has been excluded from ELF research (cf. House 2010; Jenkins et al. 2011). Such a perspective will imply that "[n]ot all ELF users are equally communicatively successful," so that the question arises to what extent the "relative ability of ELF users” (McNamara 2012b: 6, emphasis added) affects unmediated or mediated communication.

As Anna Mauranen pointed out to me, ELF spreads of its own accord and it is not a feasible option to try and turn late bilinguals into early ones or to educate the world's ELF majority to be more amenable to interpreter needs. There is, therefore, a clear need for an ELF pedagogy in interpreter training. ${ }^{5}$ I should like to add to this that there is also an incentive for ELF research to look into what is actually behind interpreter and ELF speaker perceptions of dissatisfactory expression. Interpreters do have a point in putting their finger onto the production dimension. In fact, interpreting studies has a long tradition in cognitive research into multilingual comprehension and production processes and the differences between them (cf. Braun and Kohn 2012). Schema-driven top-down processes are a powerful mechanism on the reception side, which more often than not override surface-level representations. When it comes to production, however, the baselevel process from mental propositions to surface-level verbalization becomes crucial. Against this background, it seems plausible that ELF speakers may appear to be successful from the point of view of (mutual) intelligibility, but are less so when looked at from the point of view of express-ability. As suggested by TFSbased research on bilingualism, shifting the focus of investigation onto expressability (and the various factors by which it is influenced) may, therefore, complete the picture and description of ELF communication.

\section{References}

Albl-Mikasa, Michaela. 2009. Who's afraid of ELF: “Failed” natives or non-native speakers struggling to express themselves? In Michaela Albl-Mikasa, Sabine Braun \& Sylvia Kalina (eds.), Dimensionen der Zweitsprachenforschung - Dimensions of Second Language Research. Festschrift für Kurt Kohn, 109-129. Tübingen: Narr.

5 To the best of my knowledge, interpreter training courses have started to give students experience of non-native speaker source speeches so that they can learn to cope with foreign accents, but there is, as yet, no systematic ELF-oriented pedagogy. At the ZHAW (Zurich University of Applied Sciences), a pilot course has started in the winter term of 2012 and a paper on preliminary suggestions for an ELF pedagogy in interpreter training has been submitted (Albl-Mikasa submitted). 
Albl-Mikasa, Michaela. 2010. Global English and English as a lingua franca (ELF): Implications for the interpreting profession. trans-kom 3(2). 126-148.

Albl-Mikasa, Michaela. 2012. The importance of being not too earnest. A process- and experience-based model of interpreter competence. In Barbara Ahrens, Michaela Albl-Mikasa \& Claudia Sasse (eds.), Dolmetschqualität in Praxis, Lehre und Forschung. Festschrift für Sylvia Kalina, 59-92. Tübingen: Narr.

Albl-Mikasa, Michaela. Forthcoming. The non-native ELF speakers' restricted power of expression - A handicap to the interpreters' processing.

Albl-Mikasa, Michaela. Submitted. The need for an ELF pedagogy in interpreter training.

Bartlett, Frederic Charles. 1932. Remembering: A study in experimental and social psychology. Cambridge: Cambridge University Press.

Basel, Elvira. 2002. English as lingua franca. Non-native elocution in international communication. A case study of information transfer in simultaneous interpretation. Vienna: University of Vienna doctoral thesis.

Bent, Tessa \& Ann Bradlow. 2003. The interlanguage speech intelligibility benefit. Journal of the Acoustical Society of America 114. 1600-1610.

Braun, Sabine \& Kurt Kohn. 2012. Towards a pedagogic corpus approach to business and community interpreter training. In Barbara Ahrens, Michaela Albl-Mikasa \& Claudia Sasse (eds.), Dolmetschqualität in Praxis, Lehre und Forschung. Festschrift für Sylvia Kalina, 185-204. Tübingen: Narr.

Brown, Gillian \& George Yule. 1983. Discourse analysis. Cambridge: Cambridge University Press.

Bylund, Emanuel \& Scott Jarvis. 2011. L2 effects on L1 event conceptualization. Bilingualism: Language and Cognition 14(1). 47-59.

Carrol, Mary \& Christiane von Stutterheim. 2003. Typology and information organisation perspective taking and language-specific effects in the construal of events. In A. Ramat (ed.), Typology and second language acquisition, 365-402. Berlin \& New York: Walter DeGruyter.

House, Juliane. 1999. Misunderstanding in intercultural communication: Interactions in English as a lingua franca and the myth of mutual intelligibility. In Claus Gnutzmann (ed.), Teaching and learning English as a global language, 73-89. Tübingen: Stauffenburg.

House, Juliane. 2002. Developing pragmatic competence in English as a Lingua Franca. In Karlfried Knapp \& Christiane Meierkord (eds.), Lingua franca communication, 245-267. Frankfurt am Main: Lang.

House, Juliane. 2010. The pragmatics of English as a lingua franca. In Anna Trosborg (ed.), Across Languages and Cultures (Handbook of Pragmatics 7), 363-387. Berlin \& New York: Mouton de Gruyter.

James, Allan. 2005. The challenges of the lingua franca: English in the world and types of variety. In Claus Gnutzmann \& Frauke Intemann (eds), The globalization of English and the English classroom, 133-144. Tübingen: Narr.

Jenkins, Jennifer, Alessia Cogo \& Martin Dewey. 2011. Review of developments in research into English as a lingua franca. Language teaching: Surveys and Studies 44(3). 281-315.

Katz, Jerrold J. 1978. Effability and translation. In Franz Guenthner \& M. Guenthner-Reutter (eds.), Meaning and translation. Philosophical and linguistic approaches, 191-234. London: Duckworth.

Kecskes, Istvan \& Tunde Papp. 2000. Foreign language and mother tongue. Mahwah, NJ: Erlbaum. 
Kohn, Kurt. 2011. English as a lingua franca and the Standard English misunderstanding. In Annick De Houwer \& Antje Wilton (eds.), English in Europe today. Sociocultural and educational perspectives, 72-94. Amsterdam \& Philadelphia: John Benjamins.

Kress, Christian. 2010. Analyzing comprehension problems in Midwestern discussions. Tübingen: Tübingen University MA thesis.

Kroll, Judith F. \& Erika Stewart. 1994. Category interference in translation and picture naming: Evidence for asymmetric connections between bilingual memory representations. Journal of Memory and Language 33. 149-174.

Kurz, Ingrid \& Elvira Basel. 2009. The impact of non-native English on information transfer in SI. Forum 7(2). 187-212.

Lantolf, James P. 2006. Sociocultural theory and L2. State of the art. Studies in Second Language Acquisition 28. 67-109.

Levelt, Willem. 1989. Speaking. Cambridge, MA: MIT Press.

Mauranen, Anna. 2012. Exploring ELF. Academic English shaped by non-native speakers. Cambridge: Cambridge University Press.

McNamara, Tim. 2012a. English as a lingua franca: The challenge for language testing. Journal of English as a Lingua Franca 1(1). 199-202.

McNamara, Tim. 2012b. At last: Assessment and English as a lingua franca. In Book of Programme and Abstracts, ELF5, The Fifth International Conference of English as a Lingua Franca, 24-26 May. Istanbul: Bogazici University.

Pavlenko, Aneta. 2005. Bilingualism and thought. In Judith F. Kroll \& Annette de Groot (eds), Handbook of bilingualism: Psycholinguistic approaches, 433-453. New York: Oxford University Press.

Pickering, Lucy. 2006. Current research on intelligibility in English as a lingua franca. Annual Review of Applied Linguistics 26. 219-233.

Ranta, Elina. 2006. The "attractive" progressive - Why use the -ing form in English as a lingua franca. Nordic Journal of English Studies 5(2). 95-116.

Recanati, François. 2003. The limits of expressibility. In Barry Smith (ed.), John Searle, 189-213. Cambridge: Cambridge University Press.

Reithofer, Karin. 2010. English as a lingua franca vs. interpreting - Battleground or peaceful co-existence. The Interpreters' Newsletter 15. 143-157. www.openstarts.units.it/dspace/ handle/10077/4731 (accessed 15 June 2012).

Salakhyan, Elena. 2012. The emergence of Eastern European English. World Englishes 31(3). 331-350.

Searle, John. 1969. Speech acts. An essay in the philosophy of language. Cambridge: Cambridge University Press.

Seidlhofer, Barbara. 2011. Understanding English as a lingua franca. Oxford: Oxford University Press.

Slobin, Dan I. 1996. From “thought and language" to "thinking for speaking”. In John J. Gumperz \& Stephen C. Levinson (eds.), Rethinking linguistic relativity, 70-96. Cambridge: Cambridge University Press.

Slobin, Dan I. 2003. Language and thought online: Cognitive consequences of linguistic relativity. In Dedre Gentner \& Susan Goldin-Meadow (eds.), Language in mind: Advances in the study of language and thought, 157-192. Cambridge, MA: MIT Press.

Sperber, Dan \& Deirdre Wilson. 1995 [1986]. Relevance. Communication and cognition. Oxford: Blackwell. 
von Stutterheim, Christiane \& Ralf Nüse. 2003. Processes of conceptualization in language production: Language-specific perspectives and event construal. Linguistics 41(5). 851-881.

Taylor, Christopher. 1989. Towards a typology of speakers. In Deanna Lindberg Hammond (ed.), Coming of age. Proceedings of the 30th Annual Conference of the American Translators Association, 183-188. Medford, NJ: Learned Information.

Van Dijk, Teun A. \& Walter Kintsch. 1983. Strategies of discourse comprehension. New York: Academic Press.

Widdowson, Henry G. 2004. Text, context, pretext. Oxford: Blackwell.

\section{Bionote}

Michaela Albl-Mikasa is Professor of Interpreting Studies at the Zurich University of Applied Sciences (ZHAW), Switzerland. She holds degrees from the universities of Heidelberg (Dipl.-Dolm. in Conference Interpreting), Cambridge (MPhil in International Relations), and Tübingen (Dr Phil in Applied Linguistics). Her dissertation on a cognitive-linguistic model of consecutive interpreting received the German Society of Applied Linguistics (GAL) award in 2006. Her current research interests focus on interpreter competence, the implications of English as a lingua franca for interpreters and interpreter processing, and the implications of psycholinguistic research into bilingualism for the study of ELF. 